\title{
AUTONOMOUS SHUTTLES FOR URBAN MOBILITY ON DEMAND APPLICATIONS - ECOSYSTEM DEPENDENT REQUIREMENT ELICITATION
}

\author{
A. Grahle ${ }^{1, \otimes}$, Y.-W. Song ${ }^{2}$, K. Brüske ${ }^{1}$, B. Bender ${ }^{2}$ and D. Göhlich ${ }^{1}$ \\ ${ }^{1}$ Technische Universität Berlin, Germany, ${ }^{2}$ Ruhr-Universität Bochum, Germany \\ $\triangle$ alexander.grahle@tu-berlin.de
}

\begin{abstract}
Future transport will change drastically with the introduction of automated vehicles. Here, Autonomous Mobility on Demand (AMoD) will play a major role, requiring a radical change of vehicle design, with many different conceivable concepts. This technology shift holds high potentials and high risks. Uncertainties about future usage profiles, operator and customer requirements have to be dealt with. An approach to elicit initial requirements for future vehicle concepts considering the entire ecosystem is introduced. The applicability is shown for a specific urban mobility scenario.
\end{abstract}

Keywords: autonomus mobility, urban transport, requirements management, early design phase, decision making

\section{Introduction and motivation}

Individual mobility is an important economic factor as well as a symbol of personal freedom and independence. In German metropolitan regions, $60 \%$ of all person kilometers are either covered as vehicle driver or as passenger (Nobis and Kuhnimhof, 2018). This leads to a high number of vehicles on the road causing the following problems: congestions, deteriorating air quality, over proportioned space usage and safety issues. Private vehicles are parked most of the time. According to recent statistics the average operating time in Germany is 46 minutes per day (Nobis and Kuhnimhof, 2018). In Berlin for example, 1.21 million private vehicles are registered (KBA, 2019), resulting in 1.17 million parked cars on average. Considering space is concise in urban areas, the number of parked private vehicles play an important role. In the coming years, both the proportion of urban inhabitants (United Nations, 2018) and mobility demand (van Audenhove et al., 2018) are expected to increase, aggravating the problems of the transport system. Public Transportation (PT) offers a much higher utilization and therefore more efficient space and infrastructure usage, causing less environmental impact. However, PT is lacking the flexibility, privacy and comfort of private vehicles. A technological option to bridge this gap is Autonomous Mobility on Demand (AMoD). This service holds the potential to increase the utilization rate of vehicles compared to privately owned cars while improving privacy, comfort and flexibility in comparison to PT. The International Association of Public Transport (UITP) concludes that equal urban mobility demands can be achieved using $80 \%$ less vehicles (UITP, 2017). On the contrary, these improvements could be diminished by rebound effects like a modal shift from PT to AMoD. Thus, the technology could even lead to more vehicles, more congestion and higher energy consumption (Leich and Bischoff, 2018; Pakusch et al., 
2018). When it comes to safety, autonomous vehicles hold the potential to significantly reduce fatalities in traffic (Kyriakidis et al., 2015). However, it must also be noted that safety issues are currently the biggest challenge for both, development and approval of autonomous vehicles (Hulse et al., 2018). With regard to social implications on the one hand, autonomous driving could improve the availability of affordable mobility, on the other hand, job losses and exclusivity of the services could be a burden on social welfare (Schreurs and Steuwer, 2015). Apparently, AMoD holds both, potentials and risks. However, political, technical and social decisions towards this technology need to be made today. An example for the technical level is the infrastructure required. To enable communication between autonomous vehicles and infrastructure, mobile communication networks along roads and infrastructure capable of wayside communication, such as traffic lights and signs, are required. So operators as well as local governments have to consider this in their long-term planning. Additionally, social implications like the loss of driver workplaces need to be addressed early so that solutions can be found for those affected. Finally, there adaptations to the legal framework are necessary (Lin, 2015; Wachenfeld et al., 2015). All of these tasks require an understanding on the actual requirements for and characteristics of the technology. Nevertheless, defining "the right technology" for AMoD today is fraught with high uncertainties since the objectives and the knowledge about the technology are very vague yet. A survey with transportation planners from the 25 largest metropolitan areas in the US show, that none of them consider autonomous driving and its implications in their long term planning. Mainly due to the aforementioned uncertainty (Guerra, 2016). It is obvious, that product development as well as transportation planning within dynamic environments require new approaches to decision-making in early stages of development - taking interactions and interdependencies of all objectives described above into account. Conflicting objectives between user- and operator related, technical, social and ecological aspects need to be solved. Furthermore, it is crucial to determine potential impacts and risks of introducing a disruptive technology change. This paper presents a methodological approach to handle these challenges by deriving initial requirements for future vehicles for urban AMoD applications based on different scenarios.

\section{State of the art for AMoD shuttles}

Vehicle automation is ranging from taking over small and redundant driving tasks up to a complete replacement of the driver. In this work we focus exclusively on SAE level 4 and 5 automation (SAE International, 2018), where the driver workspace is omitted. Several different applications for this technology are conceivable. The continuation of private ownership of passenger cars is one possibility, which, however, does not necessarily result in a higher resource and space efficiency. A more promising use case is on demand shuttle service, where vehicles operate in a fleet within a defined area and pick up passengers when requested (van Audenhove et al., 2018). This service is comparable to present day Mobility on Demand (MoD) applications.

$\mathrm{AMoD}$ is part of the sharing economy, specifically of ride sharing. In contrast to bike or car-sharing, where the vehicle itself is the object of the service, ride sharing aims to offer available seats in vehicles in order to increase vehicle utilization (Cohen and Kietzmann, 2014). Conventional ridesharing allows car owners to share trips with people going in the same direction. This is established for plannable journeys, for instance on the way to work or holiday trips. In urban areas, Mobility on Demand (MoD) is a promising type of ridesharing. The concept is based on the idea that users are picked up and dropped off anywhere in the service area while sharing the vehicle with other users. The vehicles are owned by a commercial operator and operated by employed drivers. Therefore, MoD services are in between PT and taxi services. Already today, MoD-services start gaining popularity. With a breakthrough of autonomous driving, these services will likely keep expanding due to cheaper prices and an even higher service flexibility (Basu et al., 2018). Future $\mathrm{AMoD}$ services bear the potential to improve urban mobility i.e. by reducing congestions, required parking space and air pollution (Bischoff and Maciejewski, 2016; van Audenhove et al., 2018). However, a new generation of vehicles, designed specifically for this application, is required. For these vehicles (AMoD shuttles) we assume a battery electric drive train since zero emission vehicles are sought for especially when considering PT in urban areas (Göhlich et al., 2018). In this paper, we develop an approach to specify changes on technical functions that go along with the 
introduction of AMoD vehicles. To clarify technical implications, we elaborate in the following three affected functional groups of these vehicles.

\subsection{Communication and navigation}

The route planning system of the vehicle needs to identify an optimal route based on its passenger's destinations as well as the current traffic situation. Hence, it needs to be highly flexible in order to react within short periods of time to events like new bookings or traffic conditions. It then must be able to adapt its current route as efficiently as possible. Therefore, a close link to the booking system as well as big data integration (traffic, other vehicles, weather) are crucial (Flügge, 2016). While the navigation system experiences only small changes compared to existing vehicles, the communication must be completely rethought for AMoD. Without a driver, all means of communication are within the responsibility of the vehicle. This includes both communication with passengers and external entities. The external entities include other automated vehicles as well as infrastructure (Färber, 2015). External communication also includes vehicle to person communication. Besides verbal communication, non-verbal communication forms such as anticipatory actions, facial expressions, body language and hand signs play a major role (Färber, 2015). They have to be interpreted and possibly imitated or sufficiently substituted by autonomous vehicles to ensure safe traffic.

\subsection{Passenger compartment}

The interior concept needs to accommodate the maximum permissible number of passengers with attractive user experience and appropriate comfort. People can generally be transported standing, sitting or lying down and they can be oriented to the front, to the rear or sideways (Winner and Wachenfeld, 2015). Ideally, a flexible seating arrangement, i.e. with rotatable and sliding seat shells is desirable, since this would allow for a private as well as social cabin layout, thus enabling the consideration of passenger preferences (Hensley et al., 2017). Furthermore, safe transport and storage of luggage needs to be ensured. In order to increase the comfort and thus the attractiveness of the vehicle for potential users, further functions, such as WIFI, screens for entertainment or tables to put a notebook on are conceivable. Some authors even debate concepts decoupling the vehicle body from the environment. In a windowless cab, for example, a virtual environment could be created for advertising or relaxation purposes (Winner and Wachenfeld, 2015). The air conditioning of the cabin is a basic comfort function, crucially influencing the well-being of passengers. A constant temperature level for the interior should be provided. However, it could also be beneficial to implement different air conditioning zones or heat and cool passengers individually via contact surfaces in the seat. Another crucial measure to raise user acceptance is to ensure for a clean and hygienic interior. Design solutions such as dirt-repellent surfaces or avoiding dirt-collecting edges and corners are feasible and should be coupled with frequent manual or automated cleaning processes. The access system allows passengers to mount and dismount the vehicle, a process which should be mainly automated. Access authorization via mobile applications, access cards or person recognition using face or fingerprint recognition (Barthelmes et al., 2017) needs to be considered, too.

\subsection{Propulsion system}

In autonomous shuttles, without a driver at the steering wheel, the requirements on vehicle dynamics change substantially (Barthelmes et al., 2017). The entire propulsion system can be designed for the specific conditions of the application area. Therefore, the electric motor needs to provide enough power to ensure sufficient but smooth acceleration and allow for operation at maximum speed, taking into account maximum slopes in the area of operation as well as the vehicles maximum payload. Engineering design can therefore focus on energy efficiency as opposed to optimizing the driving experience. Various arrangements of motor(s) are conceivable and can be adapted to the overall layout and the required drive train power. Rightsizing of the battery is of major importance, due to both its high price and weight. Battery sizing is generally dependent on the respective charging strategy (Göhlich et al., 2019). Since $\mathrm{AMoD}$ vehicles operate in a predictable manner and could be able to reject journeys that will exceed their remaining range, a small safety buffer is sufficient. Hence, the design task is to balance cost and weight 
reduction with the maximum non-stop operating time. Two charging strategies come into consideration, namely depot charging where vehicles return to a depot during operational breaks, and opportunity charging which requires charging infrastructure distributed across the operational area. Obviously, automation of the respective charging process is desirable. In both cases a high charging power is required to reduce unproductive dwell-times (Göhlich et al., 2019).

\section{Initial requirements definition}

Engineering design methodologies propose to start product development with the definition of requirements in order to clarify and specify the task. In addition to creativity-techniques, methods based on experience or opinions and observation are often proposed for the elicitation of initial requirements (Pohl and Rupp, 2016). The results have to be specified further, structured and analyzed by using appropriate methods (Song et al., 2019b). For requirements elicitation of innovative systems, both approaches should be combined, since the second approach alone usually results in limited innovations based on comparable predecessor products. Especially complex products like automobiles are generally created by incremental modifications of solutions matured over several product generations, since novelty introduces risks into the design and development process (Eckert et al., 2010). This is described as product generation development (Albers et al., 2015). Dealing with uncertainties and resulting risks starts with the initial requirements definition and is one of its biggest challenges. High degree of novelty leads to lack of definitions, i.e. "things about the system in question that have not been decided or specified" and especially to lack of knowledge, i.e. "facts that are not known, or are known only imprecisely" (McManus and Hastings, 2006). Many of these uncertainties can only be reduced with progressing development process - known as co-evolution of problem and solution (Dorst and Cross, 2001). General approaches to handle uncertainties can be derived from treatment strategies from risk management. The selection of an appropriate risk treatment strategy for the process of requirements definition is influenced by the context, e.g. macroeconomic impact, corporate risk culture / willingness to take risks, expectation of technology / innovation, product complexity, etc. (Song et al., 2019a). Based on the descriptions by (Muschik, 2011; VDI, 2018), the procedure of automotive manufacturers can be interpreted as a predominantly proactive treatment strategy. Since automobiles are highly influenced by exogenous constraints like changing regulations, consumer trends, technological innovations and market changes, it is crucial to analyze these constraints and predict their long term development as early as possible. Hence, this is the first activity when defining initial requirements for a new car concept. The second activity aims at developing product strategies as well as managing and developing new technologies or innovations (endogenous constraints). The third activity addresses the integration of exogenous and endogenous constraints and deriving initial requirements which describe a profile of fundamental product parameters, like performance, main dimensions, weight and fuel consumption as well as foreseen technologies. It thereby specifies the car's strategic position in its future competitive environment.

Vehicles for AMoD deployment fundamentally differ from conventional vehicle design and also lack predecessors to base incremental modifications on. In this case, foresight tools such as scenario technique are a proper approach to specify relevant ecosystems for vehicle development. (Laamanen, 2017). Different scenarios are anticipated in which the use cases, as represented by existing boundary conditions and requirements, change radically. In case of $\mathrm{AMoD}$ disruption can be expected with regard to user behavior as well as the application environment (traffic, infrastructure, regulations) compared to existing mobility concepts. Following the approach of the scenario technique, the initial requirement definition has to start with an analysis of those influencing areas and the elicitation of requirements arising from them.

\section{Requirements elicitation for AMOD shuttles}

The novelty of AMoD opens up new degrees of freedom for vehicle design. Simultaneously, best practices and design guidelines for conventional vehicles might lose applicability. Our approach, shown in Figure 1, is based on an analysis of the relevant ecosystem using elements of scenario planning.

The key of this approach is analyzing a possible future condition not just by one visionary assumption but by estimating the effects of as many opposing trends and assumptions as possible. Thereby a much more reliable framework for decision making can be created (Gausemeier et al., 1998). Over time, this method 
has been adapted and applied to a number of different fields including systems engineering (Graessler et al., 2016) and for requirement planning for products with unusually long product development cycles (Gräßler and Scholle, 2016). Furthermore, this method was successfully used for the requirement elicitation in aircraft design (Randt, 2015), where decisions have to be taken under high uncertainties with high impact on product safety. These two examples have a lot in common with the problem at hand, in particular the need to make valid statements about a product whose market launch is far in the future. Therefore, we developed an adapted approach for AMoD requirement elicitation using this technique. Our approach features four phases: First, the ecosystem of the vehicle concept is aggregated. The second component of the requirements analysis deals with the development of three scenarios representing different application modes and boundary conditions for the AMoD shuttles. Thirdly the behavior of influencing factors within the scenarios is analyzed, hence generating quantitative and qualitative initial requirements. Fourthly, these initial requirements can be mapped onto design drivers to create specific requirements. In this paper, we demonstrate the application of this approach to one exemplary scenario.

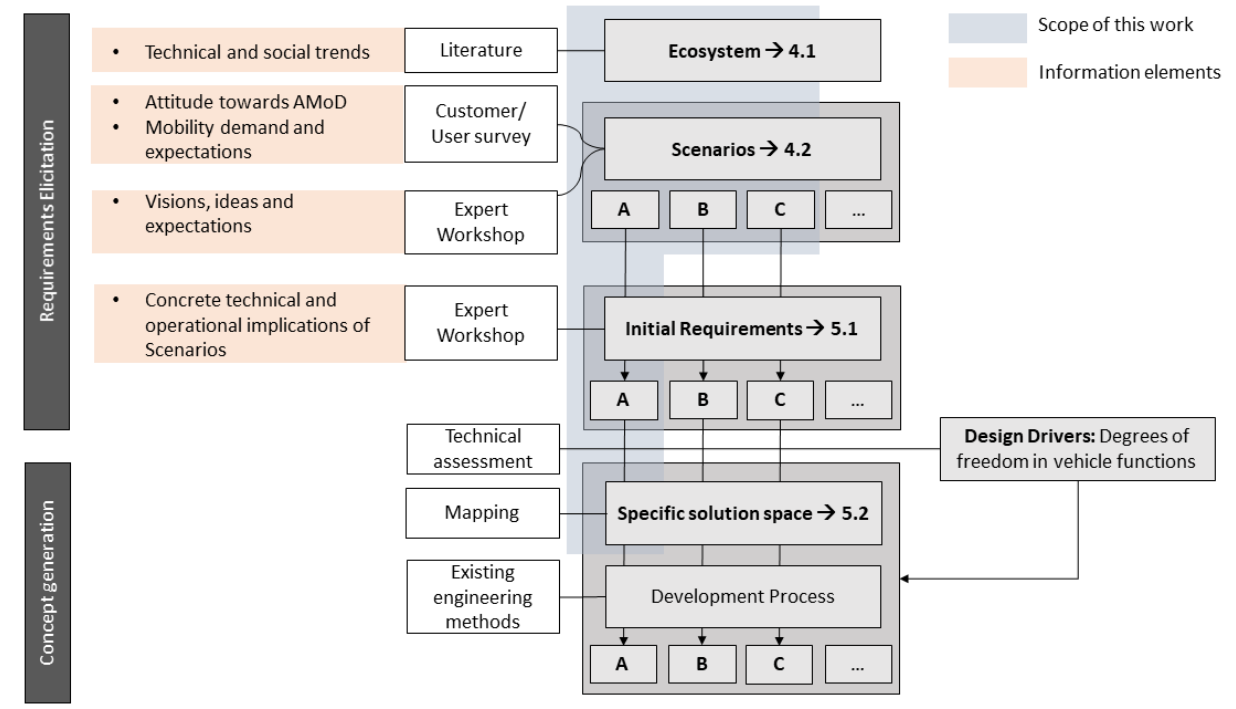

Figure 1. Approach with reference to respective sections

\subsection{The ecosystem of AMoD shuttles}

The vehicle ecosystem is the basis to elicit all relevant influencing factors. Gausemeier et al. (1998) define this process as scenario-field analysis and identify three categories of influencing factors being industry, industrial environment and global environment. It is not the aim of this work to foresee the industrial process for the production of AMoD vehicles. Instead, our focus is on the requirements elicitation with regard to different scenarios. As shown in Figure 2, seven groups of influencing factors are identified for this work.

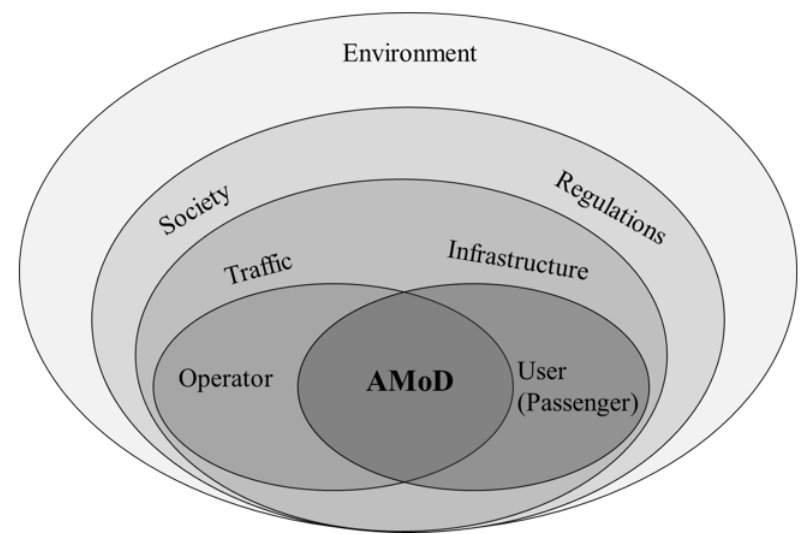

Figure 2. Ecosystem for AMoD shuttles (based on van Notten et al., 2003)
Users consume the mobility service.

An operator owns vehicles, plans the operation and represents the link between vehicle and User. $\mathrm{He}$ is the direct customer of the vehicle manufacturer.

Traffic describes the unity of all participants in urban traffic Infrastructure includes the road and its control facilities as well as charging stations.

Society is understood as the whole of people in the considered area as well as their democratic representatives. Regulations place constraints on vehicle specifications. These must be met in order to obtain road approval.

An intact Environment is the basis for healthy living conditions. Accordingly, a negative influence must be reduced as far as possible 


\subsection{Scenario development}

There are several different approaches on how to develop scenarios (Bishop et al., 2007). Since we are in direct contact with representatives of the operator, the users and the local government as well as design experts, we need a way to harness their expertise and visions in a suitable process. Hence, we chose a combination of literature review for a brief assessment of the general conditions followed by customer and user surveys and finally judgement methods like visualization and creative methods within a role play (Bishop et al., 2007) during a one-day expert workshop. In this way we defined three scenarios with the aforementioned knowledge carriers by collecting estimations and predictions of future AMoD use cases. These were then enlarged and detailed using creative methods until comprehensive and credible scenarios evolved. These will be briefly described in the following. We have access to detailed information about Berlins transport system (individual motorized transport, MoD services and PT). Hence, all three scenarios considered are based in Berlin, the largest city of Germany.

\subsubsection{Scenario A) - Mixed traffic}

Mixed traffic describes the coexistence of autonomous and non-autonomous vehicles. In analogy to the current situation, most of these vehicles are privately owned. PT has about the same share in the modal split as today. AMoD shuttles are operated only by the PT operator due to legal restrictions comparable to the current restrictions on MoD admission in German cities. This scenario only performs minor variations on the present urban traffic situation, most relevant is the absence of technical and regulatory restrictions on automated vehicles.

\subsubsection{Scenario $B)-A M o D$ and $P T$ only}

This scenario implies major political and regulatory changes in favor of AMoD and PT in the urban area. Private vehicles are banned from inner city roads. Autonomous shuttles completely replace motorized individual traffic. Autonomous PT handles the major share of the modal split. AMoD shuttles serve in two modes: Firstly, there is a designated service to supplement PT as a commuter system for the first and last mile (especially in the outskirts where the distances between houses and PT main lines are long). Secondly, a service is offered, which provides a more flexible and comfortable alternative to PT. In addition to the users who want improved but still affordable multi modal (public) transport, there is a growing share of users willing to pay extra for privacy and comfort comparable to a private car. The PT operator is the largest operator of $\mathrm{AMoD}$, offering both service types. Additionally, there is a number of smaller operators entering the market with focus on the latter service model.

\subsubsection{Scenario C) - Replacement of $P T$ by $A M O D$}

While the boundary conditions remain constant compared to scenario B), PT will be completely replaced by $\mathrm{AMoD}$. Even though this was not planned in the first place, the higher flexibility and more comfortable conditions of $\mathrm{AMoD}$ could entice away more and more customers from PT, thereby creating a viscous circle eventually leading to the bankruptcy of PT operators (also described in (Basu et al., 2018; Leich and Bischoff, 2018). This puts a focus on AMoD shuttles with higher capacity to handle the large mobility demand using the existing road infrastructure. To avoid overcapacity on the main roads, platooning of several vehicles with extremely small distances between them becomes a necessity.

\section{Exemplary results}

We go into detail with scenario A) and describe the design process based on it. For the other scenarios the approach is used accordingly and is not described here. We detail the background for Scenario A, describe the initial requirements as derived from the scenario and then elaborate on the specific solution space.

\subsection{Detailed background for scenario A}

In Scenario A, the strategy of the operator is based on both enticing away customers from private cars and offering a supplement to existing PT in order to make it more attractive (first and last mile). Therefore, it is in the operator's interest to create incentives for car owners. In our study the operation area is limited to the city of Berlin, making a top speed of more than $80 \mathrm{~km} / \mathrm{h}$ irrelevant. Moreover, this 
restriction limits the maximum distance covered by vehicles. To avoid the expensive utilization of new depots, the AMoD fleet constantly remains in service. Cleaning, checks and maintenance events are scheduled in the off-peak times. This strategy makes opportunity charging infrastructure across the area of operation inevitable. In the early phase of the service, customers mainly move away from taxis or use the shuttles as a replacement for PT, looking for a quick and affordable ride. This is somewhat contrary to the target of the operator. Fully winning car owners over to the new technology takes a longer time due to the high inhibition threshold to abolish a car. Therefore, incentives for car owners can be derived from significant improvements in service quality and price compared to making the trip in a private vehicle. Surveys show, that these incentives are time savings (no parking time and avoidance of congestions) and making better use of the time spent on the road. In general, users are willing to combine AMoD and PT as long as there are convenient platforms combining routing, booking and payment. Infrastructure and traffic are mainly unchanged compared to today. That means, roadside infrastructure is not necessarily able to communicate with the vehicles. Furthermore, a considerable amount of traffic participants are humans and therefore need tailored means of communication. The fact that congestions due to underutilized cars and accidents due to reckless driving still occur is a challenge, limiting the time saving and safety potential of $\mathrm{AMoD}$. The society demands change in the urban transport system since the majority of people is aware of the problems mentioned in the introduction. Nevertheless, policymakers hesitate putting too much pressure on car owners. This leads to an incremental adaption of regulations and laws.

The ethical question of the technology is being debated. The loss of driver jobs, especially in the taxi business, provides at short intervals resistance and even lawsuits against AMoD. On the other hand, the quality of affordable PT service can be considerably extended, e.g. to the night hours, during which mobility supply is often not possible.

\subsection{Initial requirements for scenario $A$}

Within the expert workshop described above, high level requirements were derived by analyzing the scenario-specific requirements from each environmental factor for the first scenario. Using this method, a list of 70 high level requirements was generated. Table 1 is an extract from this list.

Table 1. Fields of requirements

\begin{tabular}{|c|c|c|}
\hline $\begin{array}{l}\text { Influencing } \\
\text { factor }\end{array}$ & Field of Requirements & $\begin{array}{l}\text { Qualitative Characteristics } \\
\text { (based on Scenario 1) }\end{array}$ \\
\hline \multirow[t]{3}{*}{ Operator } & Driving performance & Max speed equals Berlin speed limit, moderate acceleration \\
\hline & Range & 4 hours continuous operation \\
\hline & Charging strategy & Opportunity fast charging \\
\hline & & \\
\hline \multirow[t]{4}{*}{ User } & Total Cost for Ride (TCR) & $\begin{array}{l}\text { Cheaper than Taxi, combined tariffs with PT, cheaper than } \\
\text { marginal cost for trip in private vehicle }\end{array}$ \\
\hline & Comfort & Possibility of privacy, cleanliness, relaxing ambiance \\
\hline & Relative transport duration & Comparable to taxi and car \\
\hline & Additional benefits & Entertainment, working space \\
\hline \multirow[t]{2}{*}{ Traffic } & Integration in mixed traffic & Flawless communication with non-automated traffic \\
\hline & Congestion avoidance & Intelligent routing under consideration of traffic situation \\
\hline Infrastructure & Handling "unintelligent" inf. & Visual recognition of signs and signals \\
\hline \multirow[t]{2}{*}{ Society } & $\begin{array}{l}\text { Improvement of social } \\
\text { equality }\end{array}$ & $\begin{array}{l}\text { Easy accessibility for old and handicapped users } \\
\text { Ensured affordability of mobility }\end{array}$ \\
\hline & Releasing of urban space & Avoidance of depots and large charging spaces \\
\hline Regulations & Compatibility & StVO, StVZO (German road traffic act and homologation) \\
\hline \multirow[t]{2}{*}{ Environment } & Low environmental impact & High utilization of vehicles, Regenerative electricity \\
\hline & Resource efficiency & Long lifetime, easy maintainability, high recyclability \\
\hline & & \\
\hline
\end{tabular}




\subsection{Specific solution space for scenario $A$}

In this phase, the qualitative requirements from the previous subsection are mapped to the functional groups presented in section 2 Thereby, the solution space can be narrowed down to provide a better understanding of the implications of the scenario considered $n$ the actual vehicle design.

The communication and navigation systems are highly influenced by requirements resulting from the more or less unchanged traffic situation. Sufficient communication with both, car drivers and pedestrians needs to be implemented. Furthermore, the navigation has to deal with the complex behavior of human drivers to enable faster, or at least equally fast transport compared to competing means of transportation. The passenger space has a high impact on whether users accept the new mobility offer; especially in a phase where the privately owned vehicle is a reasonable and affordable option. The capacity of the vehicle has to be balanced between ensuring an acceptable fast ride with a tolerable level of privacy and the need to serve the high mobility demand in rush hour, especially as a commuter to PT main lines. This leads to a capacity of existing vans of 7-9 seated passengers. In extreme situations this can be supplemented by up to 4 standing passengers. This results in the need of adjustable seat configurations allowing for a high user privacy when needed. Also, special attention needs to be given to the assurance of a clean and hygienic environment at all times. This highly effects the layout of the interior and the selection of materials, which have to be dirt repellent and easy to clean. It also includes recognizing intolerable contamination and automatically initializing a cleaning process. A focus is put on making the time on the road more valuable. Screens for every seat allow for entertainment and work during the ride. The propulsion system is highly influenced by the limitation of the operation area to the city of Berlin. Fitting the design of the power train to the prevalent conditions leads to a rather low engine power due to a low acceleration demand (to ensure passenger comfort), moderate slopes and a maximum speed of $80 \mathrm{~km} / \mathrm{h}$. The mobility peak in the rush hour in Berlin lasts for roughly 4 hours. This is the constraint for battery dimensioning, since an economic fleet sizing will aim to have all vehicles in service at that time. So a non-stop operation of slightly more than four hours under worst conditions is the lower limit for battery sizing.

\section{Discussion and outlook}

It can be expected that autonomous vehicles will enter service within the next decades. One promising application of this technology is $\mathrm{AMoD}$, offering high potentials of improvement in service, positive environmental impact and the potential of social acceptance. Mobility solution providers need to anticipate this in their strategic planning, cities need to plan and build new infrastructure. Governments have to provide both a suitable legal framework and social security. Vehicle manufacturers will have to develop completely new vehicle concepts. The concept of AMoD is a disruptive change compared to conventional vehicle concepts and there is no clear path to determine "the right technology". Contemporary developments towards $\mathrm{AMoD}$ vehicles lack systematic consideration of these uncertainties. Apparently, this technology holds both high potentials and high risks. Especially the high uncertainties about usage profiles and actual operator and customer requirements open up a wide range of potential vehicle concepts. In this paper we introduced an approach to elicit initial requirements considering the entire ecosystem based on scenarios. We demonstrated the application for a specific scenario and provided a description of a specific solution space. While using the method, we found that the influencing factors (Table 1) are not yet sufficient to structure the design space. The formation of additional subcategories by creating more levels of abstraction or detail is one way to stimulate more precise associations. Furthermore, the quality of the results depends very much on the preliminary research of possible developments and on the expertise of the participants in the workshops. To continue this work, we will investigate the remaining scenarios using revised influencing factors. Subsequently, we will use the generated specific solution spaces for a detailed concept development. Our goal is to generate valid concepts for at least three entirely different possible application scenarios. Comparing these concepts will reveal on the one hand vehicle characteristics sensitive to use case-specific changes and on the other hand the ones which remain constant. When applying the approach to enough scenarios covering a significant proportion of conceivable development strategies, the initial conflict can be solved: the identification of the robust characteristics and the range in which 
other characteristics vary allow for a much more detailed strategy and infrastructure planning, the creation of a specific legal framework and a simplified early planning of the technology itself. Once this process is completed, the applicability of the approach to other disruptive product innovations can be explored.

\section{Acknowledgements}

Parts of this work were developed within the project "zeroCUTS" which is funded by the Deutsche Forschungsgemeinschaft (DFG, German Research Foundation) - project number: 398051144.

\section{References}

Albers, A., Bursac, N. and Wintergerst, E. (2015), "Product generation development-importance and challenges from a design research perspective", New developments in mechanics and mechanical engineering, Vienna, pp. 16-21.

Barthelmes, S., Czeh, A. and Guo, Y. (2017), Autonomes Fahren Erwartungen an die Mobilität der Zukunft, Dornier Consulting International, Berlin.

Basu, R. et al. (2018), “Automated Mobility-on-Demand vs. Mass Transit: A Multi-Modal Activity-Driven Agent-Based Simulation Approach", Transportation Research Record: Journal of the Transportation Research Board, 2018, pp. 608-618.

Bischoff, J. and Maciejewski, M. (2016), "Simulation of City-wide Replacement of Private Cars with Autonomous Taxis in Berlin”, Procedia Computer Science, Vol. 83, pp. 237-244. https://doi.org/10. 1016/j.procs.2016.04.121

Bishop, P., Hines, A. and Collins, T. (2007), "The current state of scenario development: an overview of techniques", Foresight, Vol. 9 No. 1, pp. 5-25. https://doi.org/10.1108/14636680710727516

Cohen, B. and Kietzmann, J. (2014), "Ride On! Mobility Business Models for the Sharing Economy", Organization \& Environment, Vol. 27 No. 3, pp. 279-296. https://doi.org/10.1177/1086026614546199

Dorst, K. and Cross, N. (2001), "Creativity in the design process: co-evolution of problem-solution", Design Studies, Vol. 22 No. 5, pp. 425-437. https://doi.org/10.1016/S0142-694X(01)00009-6

Eckert, C.M., Alink, T. and Albers, A. (2010), "Issue driven analysis of an existing product at different levels of abstraction", Proceedings of the DESIGN 2010, the 11th International Design Conference, Dubrovnik, Croatia, Glasgow, The Design Society, pp. 673-682.

Färber, B. (2015), "Kommunikationsprobleme zwischen autonomen Fahrzeugen und menschlichen Fahrern", In: Maurer, M., Gerdes, J.C., Lenz, B. and Winner, H. (Eds.), Autonomes Fahren, Springer Berlin Heidelberg, Berlin, Heidelberg, pp. 127-146. https://doi.org/10.1007/978-3-662-45854-9_7

Flügge, B. (2016), Smart Mobility, Springer Fachmedien, Wiesbaden, https://doi.org/10.1007/978-3-658-14371-8

Gausemeier, J., Fink, A. and Schlake, O. (1998), "Scenario Management", Technological Forecasting and Social Change, Vol. 59 No. 2, pp. 111-130. https://doi.org/10.1016/S0040-1625(97)00166-2

Göhlich, D. et al. (2018), "Design of urban electric bus systems", Design Science, Vol. 4 No. p. e15. https://doi.org/10.1017/dsj.2018.10

Göhlich, D., Fay, T.-A. and Park, S. (2019), “Conceptual Design of Urban E-Bus Systems with Special Focus on Battery Technology”, Proceedings of the Design Society: International Conference on Engineering Design, Vol. 1 No. 1, pp. 2823-2832. https://doi.org/10.1017/dsi.2019.289

Graessler, I., Hentze, J. and Scholle, P. (2016), "Enhancing systems engineering by scenario-based anticipation of future developments", SoSE and cyber physical systems (CPS), from academia to application and back, Piscataway, NJ, IEEE. pp. 1-5. https://doi.org/10.1109/SYSOSE.2016.7542938

Gräßler, I. and Scholle, P. (2016), "Enhancing scenario technique by time-variant impacts", DS 84: Proceedings of the DESIGN 2016 14th International Design Conference, Design Society, pp. 1005-1014.

Guerra, E. (2016), "Planning for Cars That Drive Themselves", Journal of Planning Education and Research, Vol. 36 No. 2, pp. 210-224. https://doi.org/10.1177/0739456X15613591

Hensley, R., Padhi, A. and Salazar, J. (2017), Cracks in the ridesharing market and how to fill them. [online] Available at: https://www.mckinsey.com/industries/automotive-and-assembly/our-insights/cracks-in-theridesharing-market-and-how-to-fill-them (accessed 1 July 2019).

Hulse, L.M., Xie, H. and Galea, E.R. (2018), "Perceptions of autonomous vehicles: Relationships with road users, risk, gender and age", Safety Science, Vol. 102, pp. 1-13. https://doi.org/10.1016/j.ssci.2017.10.001

KBA (2019), Bestand am 1. Januar 2019 nach Zulassungsbezirken und Gemeinden. [online] Available at: https://www.kba.de/DE/Statistik/Fahrzeuge/Bestand/ZulassungsbezirkeGemeinden/zulassungsbezirke_node. html (accessed 14 November 2019). 
Kyriakidis, M., Happee, R. and Winter, J.C.F.D. (2015), "Public opinion on automated driving: Results of an international questionnaire among 5000 respondents", Transportation Research Part F: Traffic Psychology and Behaviour, Vol. 32, pp. 127-140. https://doi.org/10.1016/j.trf.2015.04.014

Laamanen, T. (2017), "Reflecting on the past 50 years of Long Range Planning and a research agenda for the next 50", Long Range Planning, Vol. 50 No. 1, pp. 1-7. https://doi.org/10.1016/j.lrp.2017.02.001

Leich, G. and Bischoff, J. (2018), Should autonomous shared taxis replace buses? A simulation study, Berlin.

Lin, P. (2015), "Why Ethics Matters for Autonomous Cars", In: Maurer, M., Christian Gerdes, J. and Lenz, B. (Eds.), Autonomes Fahren: Technische, rechtliche und gesellschaftliche Aspekte, Springer, Berlin, pp. 69-85. https://doi.org/10.1007/978-3-662-45854-9_4

McManus, H. and Hastings, D. (2006), "A framework for understanding uncertainty and its mitigation and exploitation in complex systems", IEEE Engineering Management Review, Vol. 34 No. 3, p. 81. https://doi.org/10.1007/978-3-662-45854-9_4

Muschik, S. (2011), Development of Systems of Objectives in Early Product Engineering, [PhD thesis], Karlsruher Institut für Technologie.

Nobis, C. and Kuhnimhof, T. (2018), Mobilität in Deutschland-MiD Ergebnisbericht, Bonn, Berlin.

Pakusch, C. et al. (2018), "Unintended Effects of Autonomous Driving: A Study on Mobility Preferences in the Future", Sustainability, Vol. 10 No. 7, p. 2404. https://doi.org/10.3390/su10072404

Pohl, K. and Rupp, C. (2016), Requirements engineering fundamentals: A study guide for the certified professional for requirements engineering exam foundation level - IREB compliant, Rocky Nook, Santa Barbara, CA.

Randt, N.P. (2015), “An approach to product development with scenario planning: The case of aircraft design", Futures, Vol. 71, pp. 11-28. https://doi.org/10.1016/j.futures.2015.06.001

SAE International (2018), SAE J3016: Taxonomy and Definitions for Terms Related to Driving Automation Systems for On-Road Motor Vehicles, SAE International.

Schreurs, M.A. and Steuwer, S.D. (2015), “Autonomous Driving - Political, Legal, Social, and Sustainability Dimensions”, In: Maurer, M., Gerdes, J.C., Lenz, B. and Winner, H. (Eds.), Autonomes Fahren, Springer Berlin Heidelberg, Berlin, Heidelberg, pp. 151-173. https://doi.org/10.1007/978-3-662-45854-9_8

Song, Y.-W., Herzog, M. and Bender, B. (2019a), "Understanding the Initial Requirements Definition in Early Design Phases", Proceedings of the Design Society: International Conference on Engineering Design, Vol. 1 No. 1, pp. 3751-3760. https://doi.org/10.1017/dsi.2019.382

Song, Y.-W., Kossack, F. and Bender, B. (2019b), "Methodisches Entwickeln von Anforderungen in der Produktentwicklung”, DFX 2019: Proceedings. https://doi.org/10.35199/dfx2019.11

UITP (2017), Autonomous vehicles: A Potential game changer for urban mobility. [online] Available at: https://www.uitp.org/news/autonomous-vehicles-urban-mobility (accessed 14 November 2019).

United Nations (2018), World Urbanization Prospects, New York.

van Audenhove, F.-J., Rominger, G. and Korn, A. (2018), The Future of Mobility 3.0, Arthur D. Little.

van Notten, P.W.F. et al. (2003), "An updated scenario typology”, Futures, Vol. 35 No. 5, pp. 423-443. https://doi.org/10.1016/S0016-3287(02)00090-3

VDI (2018), VDI 2221 - Blatt 2: Entwicklung technischer Produkte und Systeme - Gestaltung individueller Produktentwicklungsprozesse, Beuth Verlag, Berlin.

Wachenfeld, W. et al. (2015), "Use-Cases des autonomen Fahrens", In: Maurer, M., Christian Gerdes, J. and Lenz, B. (Eds.), Autonomes Fahren: Technische, rechtliche und gesellschaftliche Aspekte, Springer, Berlin, pp. 9-37. https://doi.org/10.1007/978-3-662-45854-9_2

Winner, H. and Wachenfeld, W. (2015), “Auswirkungen des autonomen Fahrens auf das Fahrzeugkonzept”, In: Maurer, M. et al. (Hg.). (Ed.), Autonomes Fahren, pp. 265-285. https://doi.org/10.1007/978-3-662-45854-9_13 